\title{
ARC Stent Thrombosis Timing Late
}

National Cancer Institute

\section{Source}

National Cancer Institute. ARC Stent Thrombosis Timing Late. NCI Thesaurus. Code C119596.

Greater than 30 days to 1 year after stent implantation. (Cutlip DE, Windecker S, Mehran $\mathrm{R}$, et al. Clinical Endpoints in Coronary Stent Trials : A Case for Standardized Definitions. Circulation. 2007;115:2344-2351) 